\title{
Marx como referencial para análise de relações entre ciência, tecnologia e sociedade?: evitando equívocos e ampliando possibilidades na aplicação de conceitos marxianos da teoria do mais-valor no campo CTS
}

\author{
Marx as a reference for analysing relationships between science, \\ technology and society?: avoiding mistakes and expanding \\ possibilities in the application of Marxian concepts of surplus \\ value theory in the STS field
}

Hilano José Rocha de Carvalho ${ }^{1}$. Maria Zanin ${ }^{2}$. Ioshiaqui Shimbo ${ }^{2}$

\begin{abstract}
Resumo: No capitalismo contemporâneo, em que a aplicação produtiva da ciência, da técnica e da tecnologia assume um papel determinante, faz-se necessário buscar modelos de referência capazes de explicar os processos subjacentes à mesma, bem como os efeitos sociais mais amplos. Neste sentido, este artigo objetiva analisar criticamente o artigo intitulado Marx como referencial para análise de relações entre ciência, tecnologia e sociedade, apontando aspectos, face à sua tentativa de se apropriar dos conceitos marxianos da teoria do mais-valor para a compreensão crítica das relações CTS. A partir de uma confusão conceitual, fundada basicamente numa distinção deficiente entre duração, intensidade e produtividade do trabalho, os conceitos de mais-valor absoluto e relativo divergem das definições marxianas originais. Por isto e por centrar a análise na redução do valor da força de trabalho, a complexidade das relações capitalistas e o desenvolvimento social em função das mudanças científico-tecnológicas são deixados de lado.
\end{abstract}

Palavras-chave: Ciência-tecnologia-sociedade. CTS. Capitalismo. Marxismo. Teoria do mais-valor.

\begin{abstract}
In contemporary capitalism, in which the productive application of science, techniques and technology has a determinant role, it is necessary to search for reference models that are capable of explaining its subjacent processes, as well as the broader social effects. In this sense, this paper aims at critically analyzing the entitled paper Marx como referencial para análise de relações entre ciência, tecnologia e sociedade, indicating aspects, due to its attempt to appropriate the Marxian concepts of the theory of surplus value for the critical comprehension of STS relations. From a conceptual confusion, basically founded on a deficient distinction among duration, intensity and productivity of labor, the concepts of the absolute and relative surplus diverge from the original Marxian definitions. Because of this and for centralizing its analysis in the reduction of workforce value, the complexity of the capitalist relations and social development due to the scientific and technological changes are put aside.
\end{abstract}

Keywords: Science, techonology and society. STS. Capitalism. Marxism. Theory of surplus value.

\footnotetext{
${ }^{1}$ Universidade Federal de São Carlos (UFSCar), Programa de Pós-graduação em Ciência, Tecnologia e Sociedade (PPGCTS), São Carlos, SP, Brasil. E-mail: <hilanocarvalho@gmail.com>.

${ }^{2}$ UFSCAR, Núcleo Multidisciplinar Integrado de Estudos, Formação e Intervenção em Economia Solidária (NuMIEcoSol), São Carlos, SP, Brasil.
} 


\section{Introdução}

As relações entre ciência, tecnologia e sociedade não podem ser restritas à mera descrição de fatos e à identificação de atores - como esses se comportam e se relacionam, que decisões tomam -, tal como faz, mais comumente, a sociologia da ciência e da tecnologia (WINNER, 1993). A compreensão da complexa dinâmica social em decorrência das mudanças cada vez mais efetivas das inovações tecnológicas necessita apreender não apenas as condições favorecedoras ou necessárias para permitir o desenvolvimento econômico, mas desenvolver um referencial de análise crítica da realidade social, que leve em consideração as relações sociais; especialmente, as relações de produção (FEENBERG, 2009; NOVAES; DAGNINO, 2004). Afinal, no contexto do capitalismo avançado contemporâneo, a ciência, a técnica e a tecnologia passam a serem fatores produtivos mais importantes do que o próprio trabalho humano direto. O efeito evidente desse processo é a redução acelerada de oportunidades de emprego (e mesmo de trabalho) para grande parte da humanidade, gerando o chamado desemprego estrutural. Para tentar pelo menos deslindar esse fenômeno hodierno, que afeta severamente as relações sociais, Marx, já no século XIX, analisou o processo de desenvolvimento capitalista que principiava, identificando a sua lógica subjacente, com os efeitos diretos e indiretos sobre a classe trabalhadora, sendo capaz de projetar-se para o futuro e antever várias situações vivenciadas atualmente: a agudização das contradições imanentes ao desenvolvimento científico-tecnológico capitalista e as transformações nas relações sociais de produção correspondentes e vice-versa.

Por conta disso, buscar em Marx um conjunto de conceitos e categorias referenciais para a análise crítica de relações entre ciência, tecnologia e sociedade é fundamental. Entretanto, igualmente, é necessário apropriar-se devidamente do ferramental analítico-crítico marxiano para evitar equívocos ou para evitar restringir seu campo de aplicação. Neste sentido, este artigo objetiva criticar o artigo intitulado "Marx como referencial para análise de relações entre ciência, tecnologia e sociedade" (LIMA JUNIOR et al., 2014), no que se refere à sua tentativa de se apropriar dos conceitos marxianos da teoria do mais-valor (ou mais-valia) para a compreensão crítica das relações CTS.

Para tal, este artigo está dividido em duas seções subsequentes: seção um em que a teoria do mais-valor de Marx é apresentada e discutida referente aos conceitos de mais-valor absoluto, mais-valor relativo, duração, intensidade e produtividade do trabalho; seção dois em que, a partir da construção teórico-conceitual marxiana da seção um, faz-se propriamente a crítica do artigo intitulado "Marx como referencial para análise de relações entre ciência, tecnologia e sociedade", corrigindo equívocos e ampliando as possibilidades de aplicação do pensamento de Marx para se estudar as relações CTS na contemporaneidade.

Espera-se, desta forma, contribuir para uma maior compreensão das várias nuanças das relações entre ciência, tecnologia e sociedade na contemporaneidade, a partir de uma perspectiva de análise crítica centrada no conceito de mais-valor e na dialética do trabalho necessário e trabalho excedente que lhe é subjacente, bem como do devido esclarecimento dos conceitos de duração, intensidade e aumento da produtividade do trabalho. 


\section{Elementos da teoria do mais-valor de Marx}

Não se intenta neste artigo esgotar a discussão sobre a teoria do mais-valor (ou teoria do valor-trabalho) formulada por Marx, apresentando todas as suas nuanças, desdobramentos e críticas, como fizeram Rubin (1980), Cotrim (2013) e Reichelt (2013). Partindo dos conceitos e categorias fundamentais da crítica marxiana à economia capitalista, especialmente, os que se referem à dialética do trabalho necessário e trabalho excedente, objetiva-se analisar o desenvolvimento social contemporâneo sob o atual contexto da aplicação e dos impactos da ciência, da técnica e da tecnologia.

Principiando, em O Capital, Marx (2012a, p. 98-99) apresenta uma das mais lúcidas imagens para demonstrar a importância do tempo como medida-base do processo de produção de valores, subjacente a todas as atividades humanas: o experimento robinsoniano.

Preocupado em suprir suas necessidades materiais e sociais, Robinson Crusoé, isolado em uma ilha, distribui meticulosamente seu tempo disponível em suas várias atividades diárias: um quantum de tempo para pescar, outro para caçar, mais um dedicado à fabricação de instrumentos, etc. Em suma, todo o tempo de Robinson dedicado ao conjunto das suas atividades necessárias diárias corresponde ao seu tempo de trabalho necessário para que consiga reproduzir a si mesmo dia após dia, mostrando que "[...] o tempo de trabalho que custa produzir os meios de subsistência interessou, necessariamente, aos homens, em todas as épocas, embora em grau variável com o estágio do desenvolvimento" (MARX, 2012a, p. 93).

Para além do cenário idílico robinsoniano, já sob a lógica do capitalismo, a jornada de trabalho é dividida em (tempo de) trabalho necessário e (tempo de) trabalho excedente. De um lado, tem-se o trabalho necessário, que corresponde à soma do tempo de trabalho para a produção das mercadorias necessárias (meios de subsistência) à reprodução vital e social dos que trabalham. Complementarmente, de outro lado, tem-se o trabalho excedente, que, dada a jornada de trabalho, corresponde a um tempo de trabalho que excede o necessário, correspondendo ao substrato material que determina o mais-valor. Sobre isto, a Figura 1 ilustra o caso de uma jornada diária de trabalho de $8 \mathrm{~h}$ dividida em um trabalho necessário igual a $4 \mathrm{~h}$ e, consequentemente, em um trabalho excedente igual a $4 \mathrm{~h}$.

Figura 1. Divisão de uma jornada diária de trabalho de $8 \mathrm{~h}$, em $4 \mathrm{~h}$ de trabalho necessário e $4 \mathrm{~h}$ trabalho excedente

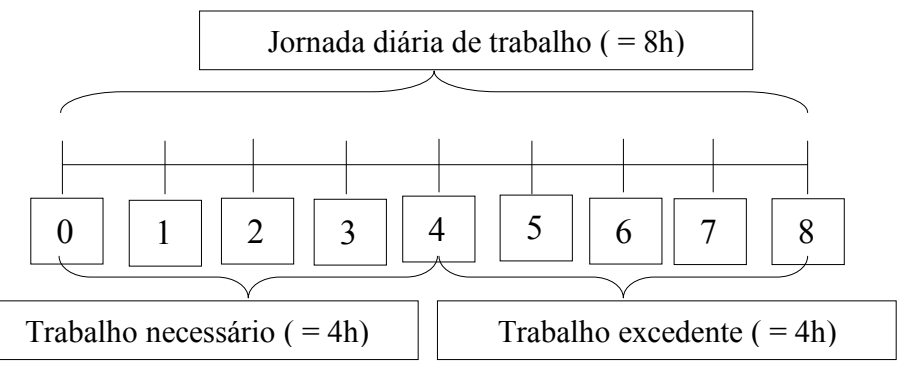

Fonte: Elaborada pelos autores. 
A partir da Figura 1, e considerando, por exemplo, o valor pago pela força de trabalho igual a $\mathrm{R} \$ 400$, o valor produzido por cada hora de trabalho é igual a $\mathrm{R} \$ 100^{3}$. Por conseguinte, uma vez que a força de trabalho é utilizada por $8 \mathrm{~h}$, a força de trabalho produz não apenas $\mathrm{R} \$$ 400 correspondentes às 4 h de trabalho necessário, mas $\mathrm{R} \$ 800^{4}$, fazendo com que o trabalho excedente de 4 h equivalha a um mais-valor de $\mathrm{R} \$ 400$, que poderá ser apropriado pelo capitalista como lucro quando da venda das mercadorias produzidas. Considerando, ademais, que, ao final das 8 h, 100 unidades de mercadorias são produzidas ou que a cada $0,08 \mathrm{~h}^{5}$ uma unidade da mesma é produzida, um valor de $\mathrm{R} \$ 8^{6}$ é adicionado a cada mercadoria produzida. Deste valor produzido e adicionado igual a $\mathrm{R} \$ 8$ a cada mercadoria, $50 \%$ ou $\mathrm{R} \$ 4$ correspondem ao valor da força de trabalho e os outros $50 \%$ ou $\mathrm{R} \$ 4$ ao mais-valor. Somando o valor adicionado e produzido de $\mathrm{R} \$ 8$ ao valor dos meios de produção reproduzidos igual a, por exemplo, $\mathrm{R} \$ 3$ - sendo $\mathrm{R} \$ 1$ correspondente ao valor da matéria-prima e $\mathrm{R} \$ 2$ correspondente ao valor dos meios de trabalho (rateio e depreciação de máquinas, ferramentas, etc.) -, o valor de cada unidade da mercadoria corresponde a $\mathrm{R} \$ 11$. Com estas informações, o exemplo da Figura 1 aparece modificado na Figura 2.

Figura 2. Produção de mercadorias e valores em 8 h de trabalho diário

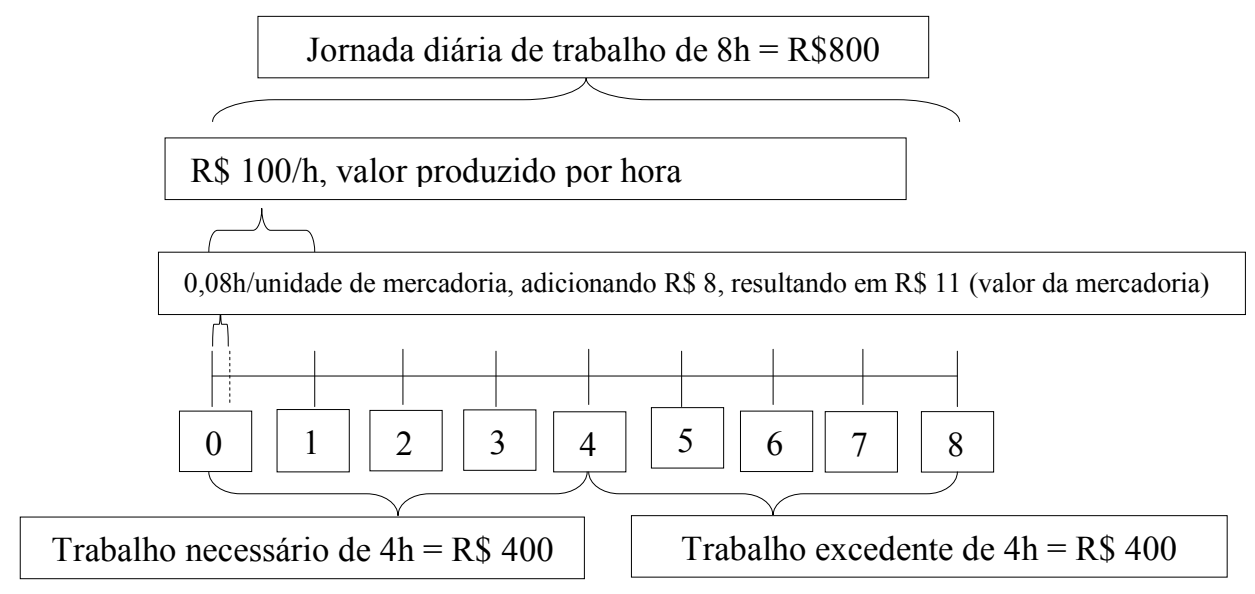

Fonte: Elaborada pelos autores.

\footnotetext{
$3^{3}=[\mathrm{R} \$ 400$ de valor da força de trabalho] / [4 h de trabalho necessário].

${ }^{4}=[\mathrm{R} \$ 100 / \mathrm{h}] \times[8 \mathrm{~h}$ de jornada diária de trabalho $]$.

${ }^{5}=$ [8h de jornada diária de trabalho] / [100 unidades de mercadorias produzidas em $8 \mathrm{~h}$ de jornada diária de trabalho].

${ }^{6}=[0,08 \mathrm{~h}$ como tempo para produção de uma unidade de mercadoria $] \times[R \$ 100 / \mathrm{h}]$.
} 
Para fins de ilustração e para facilitar o entendimento da teoria do mais-valor a ser apresentada e discutida a seguir, que costuma ser negligenciada tanto por defensores quanto por contrários à mesma, especialmente no que toca ao seu jogo matemático nuclear subjacente (fundamental para se avançar para a seção crítica dois desse trabalho), o exemplo numérico anterior, iniciado e ilustrado nas Figuras 1 e 2, será recorrentemente retomado, ampliado e alterado nos próximos parágrafos desta seção.

Dadas certas condições produtivo-econômicas, ora o tempo de trabalho necessário é maior relativamente ao trabalho excedente, ora o tempo de trabalho excedente é maior relativamente ao trabalho necessário. Tal dialética corresponde à forma lógica fundamental que se reproduz imanentemente nas relações sociais de produção capitalistas, qual seja, na luta de classes entre capitalistas (donos dos meios de produção) e trabalhadores (vendedores de força de trabalho), uma vez que, dada uma mesma jornada de trabalho, se o trabalho excedente aumenta em benefício dos capitalistas, o trabalho necessário necessariamente tem que ser reduzido em detrimento dos trabalhadores, mas se o trabalho necessário aumenta em benefício dos trabalhadores, o trabalho excedente necessariamente tem que ser reduzido em detrimento dos capitalistas. Sob este jogo antitético do trabalho necessário e do trabalho excedente, o prolongamento ou aumento da duração da jornada de trabalho para além do tempo de trabalho necessário aumenta absolutamente o mais-valor: o chamado mais-valor absoluto. Já fixando a jornada de trabalho, o mais-valor amplia-se relativamente pela redução do trabalho necessário com o aumento consequente do trabalho excedente: o mais-valor relativo. Formalmente, Marx distingue mais-valor absoluto e mais-valor relativo da seguinte maneira: "Chamo de mais-valia absoluta a produzida pelo prolongamento do dia de trabalho, e de mais-valia relativa à decorrente da contração do tempo de trabalho necessário e da correspondente alteração na relação quantitativa entre ambas as partes componentes da jornada de trabalho" (MARX, 2012a, p. 366).

Ou seja, "[...] quando se trata de mais-valia tornando excedente trabalho necessário, não basta que o capital se aposse do processo de trabalho na situação em que se encontra ou o que lhe foi historicamente transmitida, limitando-se a prolongar sua duração" (MARX, 2012a, p. 366). Tal diferenciação entre os conceitos de mais-valor absoluto e mais-valor relativo deve ser muito bem demarcada para mostrar a preponderância do mais-valor relativo no estágio atual de desenvolvimento capitalista das forças produtivas e, como ficará evidente na Seção dois, para evitar equívocos e ampliar possibilidades no uso daqueles para analisar criticamente a sociedade contemporânea.

A partir da variação ou fixação das variáveis - jornada de trabalho, trabalho necessário e trabalho excedente -, e retomando o caso ilustrativo anterior, têm-se condições favoráveis e conflitantes: de um lado, para os trabalhadores, quando do aumento do valor da força de trabalho de $\mathrm{R} \$ 400$ (pelo aumento do trabalho necessário de 4 h) ${ }^{7}$ ou da redução da jornada diária de trabalho de $8 \mathrm{~h}$ ou; de outro lado, para os capitalistas, quando da redução do valor da força de trabalho de $\mathrm{R} \$ 400$ (pela redução do trabalho necessário de 4 h) ou do aumento da jornada de trabalho de $8 \mathrm{~h}$. Se os trabalhadores trabalhassem apenas as $4 \mathrm{~h}$ correspondentes ao trabalho necessário, não haveria trabalho excedente e, por conseguinte, não haveria a produção

\footnotetext{
${ }^{7} \mathrm{O}$ que significa a melhoria das condições materiais e de vida para além dos meios de subsistência mais essenciais.
} 
de mais-valor para o capitalista. No entanto, uma vez que os trabalhadores não são donos dos meios de produção e não possuem controle sobre os processos de venda e de circulação das mercadorias, a jornada diária de trabalho deve ser necessariamente prolongada para além das 4 $\mathrm{h}$ necessárias até às $8 \mathrm{~h}$, uma vez que em $4 \mathrm{~h}$ são produzidas apenas 50 unidades de mercadorias e, considerando que R 8 são adicionados a cada uma delas - dos quais, em decorrência da relação quantitativa entre o trabalho excedente e o trabalho necessário (ou taxa de mais-valor) ser igual a $100 \%$, apenas $\mathrm{R} \$ 4$ correspondem ao valor da força de trabalho -, um valor de apenas $\mathrm{R} \$ 200^{8}$ é produzido correspondente ao valor da força de trabalho (além dos $\mathrm{R} \$ 200$ referentes ao mais-valor); isto é, apenas metade do valor total da força de trabalho é obtida em metade da jornada diária de trabalho.

Por sua vez, o interesse do capitalista é prolongar ao máximo tal produção absoluta de mais-valor para além das $4 \mathrm{~h}$. Caso fosse possível ampliar a duração da jornada diária de trabalho - por exemplo, com horas extras de trabalho - de 8 h para $9 \mathrm{~h}$, a produção absoluta de mais-valor passaria de $\mathrm{R} \$ 400$ para $\mathrm{R} \$ 500$, sem alterar o valor produzido pela força de trabalho a cada hora, que continuaria igual a $\mathrm{R} \$ 100$, como mostra a Figura 3.

Figura 3. Prolongamento ou aumento da duração da jornada diária de trabalho de $8 \mathrm{~h}$ para $9 \mathrm{~h}$, no contexto da produção absoluta do mais-valor, ampliado de $\mathrm{R} \$ 400$ para $\mathrm{R} \$ 500$

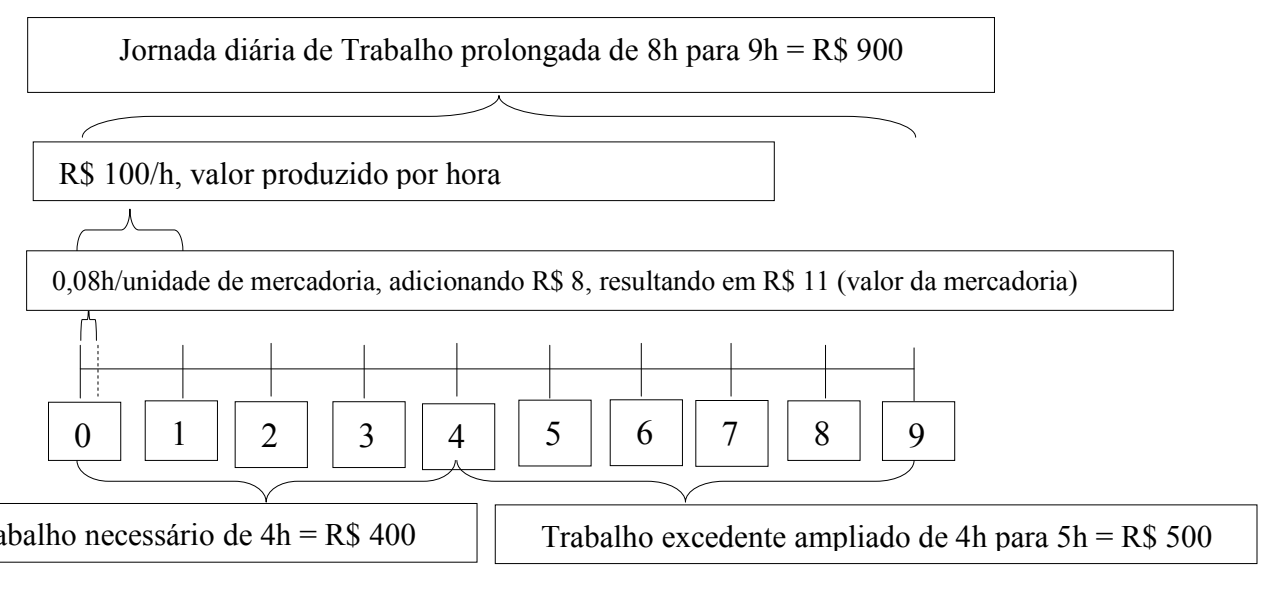

Fonte: Elaborada pelos autores.

Entretanto, o caso ilustrado pela Figura 3, o de aumentar a duração da jornada de trabalho, pode encontrar maiores ou menores constrangimentos em face das condições técnicas e tecnológicas decorrentes do estágio de desenvolvimento das forças produtivas ou das limitações

${ }^{8}=[\mathrm{R} \$ 4$ de valor de força de trabalho por mercadoria $] \times$ [50 unidades de mercadorias]. 
impostas pela legislação vigente para a duração máxima de trabalho diário. Por isto, mesmo fixando como máxima a jornada diária de trabalho de $8 \mathrm{~h}$, o capitalista buscará estratégias para reduzir o trabalho necessário de $4 \mathrm{~h}$, para aumentar consequentemente o trabalho excedente para além de $4 \mathrm{~h}$, isto é, maximizar a produção relativa de mais-valor. Daí que, no caso particular do mais-valor relativo, a variação na intensidade e na produtividade do trabalho são estratégias fundamentais para o capitalista. Apesar de guardarem semelhanças, daí a origem de possíveis confusões interpretativas, Marx distingue aumento da produtividade e aumento da intensidade precisamente, inclusive em relação à duração do trabalho. Sobre isto, Marx afirma que

[...] o aumento da produtividade e o da intensidade do trabalho atuam na mesma direção. Ambos aumentam a quantidade produzida num dado espaço de tempo. Ambos reduzem, portanto, a parte da jornada que o trabalhador precisa para produzir seus meios de subsistência ou o equivalente deles. (MARX, 2012b, p. 601).

Isto é, ambos concorrem para contrair o trabalho necessário para ampliar o trabalho excedente, mas

[...] o aumento da intensidade do trabalho pressupõe maior dispêndio de trabalho no mesmo espaço de tempo. A jornada de trabalho de maior intensidade corporifica-se, por isso, em mais produtos do que a jornada de trabalho de menor intensidade, mas da mesma duração. Sem dúvida, a jornada cuja duração não se altera fornece mais produtos, se aumenta a produtividade. Mas, neste caso, cai o valor de cada produto, por custar menos trabalho do que antes; no caso anterior, esse valor permanece inalterado, pois cada produto continua a custar a mesma quantidade precedente de trabalho. O número dos produtos aumenta, sem cair o preço da unidade (MARX, 2012b, p. 601).

Tanto o aumento da intensidade quanto o aumento da produtividade do trabalho reduzem o tempo de trabalho para produzir cada mercadoria, produzindo, por exemplo, na jornada diária de $8 \mathrm{~h}$, uma quantidade maior de valores-de-uso. No entanto, enquanto que o aumento da intensidade não altera o valor da mercadoria, de sorte que este continue a ser igual a $\mathrm{R} \$ 11$, isto não acontece sob o aumento da produtividade do trabalho. Supondo que, com a modificação do modo de produção e a melhoria das forças produtivas, os trabalhadores consigam produzir cada unidade de mercadoria não mais em $0,08 \mathrm{~h}$, mas em um tempo menor de $0,072 \mathrm{~h}$, em ambos os casos de aumento da intensidade e da produtividade do trabalho, haveria aumento da quantidade de mercadorias produzidas de 100 para aproximadamente $111,111^{9} \mathrm{em} 8 \mathrm{~h}$.

\footnotetext{
${ }^{9}=$ [8h de jornada diária de trabalho] / [0,072h como novo tempo para produção de uma unidade de mercadoria $]$.
} 
No entanto, enquanto que, no caso da intensidade do trabalho, um valor de $\mathrm{R} \$ 888,888^{10}$ será produzido aproximadamente ao final das $8 \mathrm{~h}$, no caso da produtividade do trabalho, o mesmo valor de $\mathrm{R} \$ 800,00$ de antes será produzido; ou, em outras palavras, sob o aumento da produtividade do trabalho, o valor adicionado a cada mercadoria cai de $\mathrm{R} \$ 8$ para aproximadamente $\mathrm{R} \$ 7,2^{11}$. Como a taxa de mais-valor anterior não se altera, destes $\mathrm{R} \$ 7,2$ adicionados a cada mercadoria, $R \$ 3,6$ correspondem ao valor da força de trabalho e os restantes $R \$ 3,6$ ao mais-valor. Assim sendo, com o aumento da produtividade do trabalho, o valor individual de cada mercadoria cai de $\mathrm{R} \$ 11$ para aproximadamente $\mathrm{R} \$ 10,2$. Ademais, no caso particular do aumento da intensidade do trabalho, mantendo o valor da força de trabalho igual a $\mathrm{R} \$ 400$ como antes, uma vez que a força de trabalho a cada hora passa a produzir aproximadamente $\mathrm{R} \$ 111,111^{12}$, o trabalho necessário cai de $4 \mathrm{~h}$ para aproximadamente $3,6 \mathrm{~h}^{13}$, aumentando consequentemente o trabalho excedente de $4 \mathrm{~h}$ para 4,4 h, como ilustra a Figura 4.

Figura 4. Efeito consequente da intensidade do trabalho sobre a redução do trabalho necessário de 4h para 3,6h e o aumento do trabalho excedente de $4 \mathrm{~h}$ para 4,4h, no contexto da produção relativa de mais-valor ampliado de $\mathrm{R} \$ 400$ para aproximadamente $\mathrm{R} \$ 488,88$

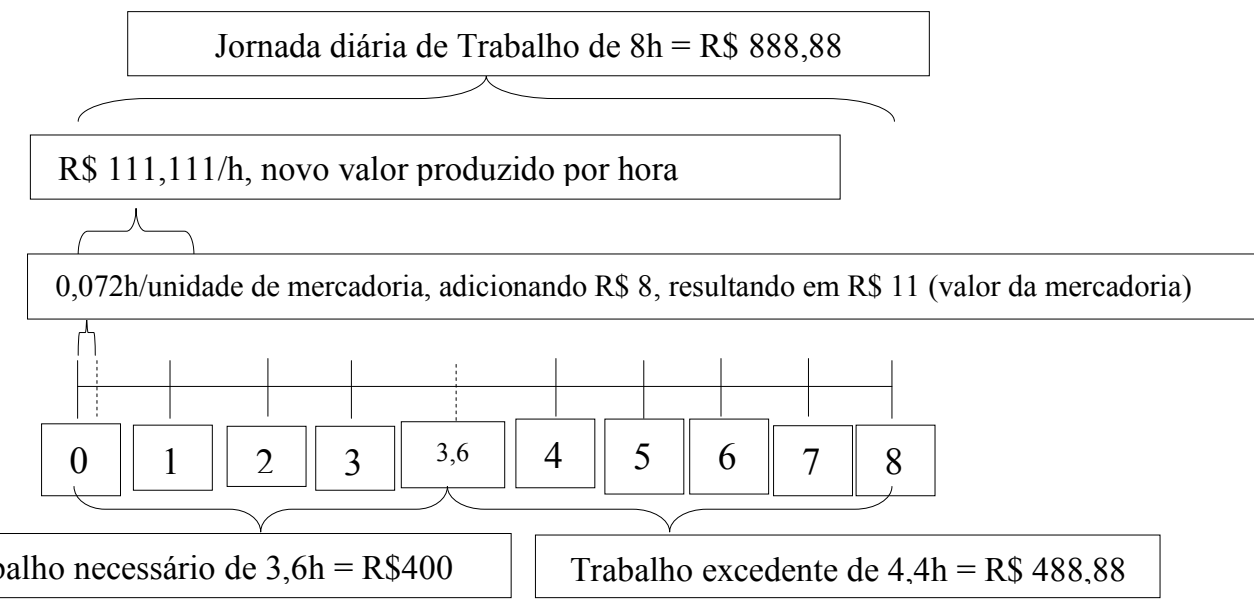

Fonte: Elaborada pelos autores.

\footnotetext{
${ }^{10}=[R \$ 8$, valor adicionado a cada unidade de mercadoria $] \times[111,111$, nova quantidade de mercadorias produzidas].

${ }^{11}=[\mathrm{R} \$ 800$, valor total produzido em $8 \mathrm{~h}] /[111,111$, nova quantidade de mercadorias produzidas $]$.

${ }^{12}=[\mathrm{R} \$ 888,888$, novo valor total produzido por hora] / [8h, jornada diária de trabalho] (intensidade do trabalho).

${ }^{13}=[\mathrm{R} \$ 400$ de valor da força de trabalho $] /[\mathrm{R} \$ 111,111 / \mathrm{h}]$ (intensidade do trabalho).
} 
$\mathrm{Na}$ Figura 4, por conta do aumento da intensidade do trabalho, alterou-se a relação quantitativa entre o trabalho excedente e o trabalho necessário, isto é, a taxa de mais-valor sobe de $100 \%$ para cerca de $122,22 \%$. Já no caso particular do aumento da produtividade do trabalho, caso o capitalista decida vender cada mercadoria por $\mathrm{R} \$ 10,2$, não haverá alteração na taxa de mais-valor. No entanto, uma vez que aquele objetiva maximizar suas chances de lucro, ele pode vender sua mercadoria mais barato do que seus concorrentes e, ainda assim, pode lucrar mais do que antes: vendê-la abaixo dos $\mathrm{R} \$ 11,00$, do seu valor social, mas acima do seu valor individual, isto é, acima de $\mathrm{R} \$ 10,2$. Supondo que ele decide vendê-la a $\mathrm{R} \$ 10,8$, então o valor total produzido em 8 h diárias de trabalho aumenta de $\mathrm{R} \$ 800,00$ para cerca de $\mathrm{R} \$ 866,666^{14}$. Por conseguinte, no caso particular do aumento da produtividade do trabalho, mantendo o valor da força de trabalho igual a $\mathrm{R} \$ 400$ como antes, uma vez que a força de trabalho a cada hora passa a produzir aproximadamente $\mathrm{R} \$ 108,333^{15}$, o trabalho necessário cai de $4 \mathrm{~h}$ para aproximadamente $3,69 \mathrm{~h}^{16}$, aumentando consequentemente o trabalho excedente de $4 \mathrm{~h}$ para 4,31h, como ilustra a Figura 5.

Figura 5. Efeito consequente da produtividade do trabalho sobre a redução do trabalho necessário de 4h para 3,69h e o aumento do trabalho excedente de $4 \mathrm{~h}$ para $4,31 \mathrm{~h}$, no contexto da produção relativa de mais-valor ampliado de $\mathrm{R} \$ 400$ para aproximadamente $\mathrm{R} \$ 466,666$

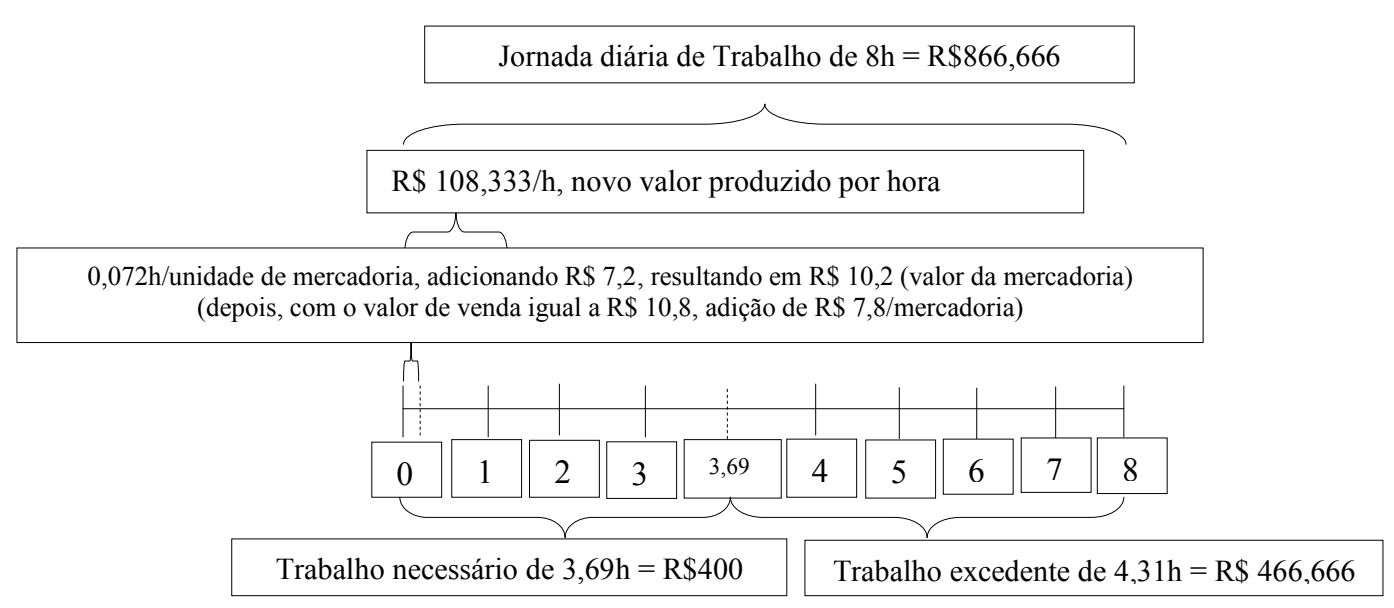

Fonte: Elaborada pelos autores.

\footnotetext{
${ }^{14}=[\mathrm{R} \$ 7,8$, valor adicionado a cada unidade de mercadoria $] \times[111,111$, nova quantidade de mercadorias produzidas].

${ }^{15}=[\mathrm{R} \$ 866,666$, novo valor total produzido por hora $/$ [8h, jornada diária de trabalho] (produtividade do trabalho).

${ }^{16}=[\mathrm{R} \$ 400$ de valor da força de trabalho $] /[\mathrm{R} \$ 108,333 / \mathrm{h}]$ (produtividade do trabalho).
} 
Em todos os casos supracitados de produção relativa de mais-valor e ilustrados nas Figuras 1, 2, 4 e 5, o capitalista cria as condições para lucrar de maneira ampliada, seja barateando as mercadorias pelo aumento da produtividade ou tornando mais intenso o trabalho alheio. Em tal contexto, tendo em vista aumentar a intensidade e/ou a produtividade do trabalho, o desenvolvimento científico e tecnológico das forças produtivas assume um papel central, fazendo com que

[...] a riqueza efetiva se manifesta antes - e isso o revela a grande indústria - na tremenda desproporção entre o tempo de trabalho empregado e seu produto, bem como na desproporção qualitativa entre o trabalho reduzido à pura abstração e o poder do processo de produção que ele supervisiona. O trabalho não parece mais tão envolvido no processo de produção quando o ser humano se relaciona ao processo de produção muito mais como supervisor e regulador. (MARX, 2011, p. 587).

Contemporaneamente, a referida antevisão de Marx "[...] diz respeito à automação, apresentada como necessária para melhorar o desempenho da empresa e garantir-lhe uma competitividade real" (LINHART, 2007). Isso decorre, conforme Romero (2007), aproximando-se de Moraes Neto (1989), do fato da ciência, da técnica e da tecnologia tornarem-se fatores produtivos decisivos na realização da subsunção real do trabalho ao capital, reforçando as relações sociais de produção dicotômicas: patrão, donos dos meios de produção, supervisionando e controlando direta ou indiretamente o fluxo de produção de valores por parte dos trabalhadores.

Coadunando-se com Postone (2014), a ciência, a técnica e a tecnologia produtivamente aplicadas assumem um caráter não apenas ideológico, mas de dominação social pelo trabalho.

\section{Equívocos e possibilidades na aplicação da teoria do mais-valor de Marx no campo CTS}

Como o próprio título do artigo em análise neste trabalho sugere precisamente, "Marx como referencial para análise de relações entre ciência, tecnologia e sociedade", Lima Júnior et al. (2014) têm por objetivo demonstrar a insuficiência das abordagens teóricas e metodológicas do campo CTS na análise da realidade social e concreta, bem como da formação em CTS (currículos), buscando no pensamento crítico de Marx novos caminhos mais adequados aos problemas decorrentes das relações entre ciência, tecnologia e sociedade; especialmente aqueles que concernem aos impactos do desenvolvimento científico-tecnológico capitalista sobre a classe trabalhadora.

As abordagens criticadas por Lima Júnior et al. (2014) estão assentadas em três mitos: (1) o da superioridade dos modelos de decisões tecnocráticas; (2) a perspectiva salvacionista da C\&T, e; (3) o determinismo tecnológico. Em (1), diz-se que as decisões baseadas no conhecimento exclusivo de tecnocratas são sempre as melhores possíveis, dispensando a participação de não-especialistas ou da população em geral afetada. Já em (2), parte-se da ideia de que o mero uso da ciência e tecnologia, por si só, gera o bem-estar social. Por fim, em (3), o desenvolvimento tecnológico influencia mudanças sociais, mas não é influenciado por aspectos sociais. A 
partir dessa classificação preliminar, Lima Júnior et al. (2014) recuperam os principais conceitos marxianos para construir um modelo de referência para pensar o campo CTS de maneira crítica, para além de uma perspectiva de neutralidade. Para tal, Lima Júnior et al. (2014) tentam apropriar-se e aplicar os conceitos de mercadoria, valor, força de trabalho, capital e mais-valor. No entanto, equívocos de definição e de interpretação aparecem justamente naquelas categorias que são centrais para a crítica empreendida por Lima Júnior et al. (2014): mais-valor absoluto e mais-valor relativo.

Supostamente baseando-se em Marx, Lima Júnior et al. (2014) diferenciam mais-valor absoluto e mais-valor relativo de uma maneira divergente da de Marx (conforme apresentados e discutidos na seção um, inclusive com exemplos numéricos),

A mais-valia produzida pelo aumento absoluto da duração ou da intensidade
da jornada de trabalho chama-se mais-valia absoluta. Por sua vez, o aumento
na mais-valia que resulta da redução da fração da jornada de trabalho em
que o trabalhador produz o valor da sua força de trabalho (mantendo-se
constante a duração e intensidade absolutas da jornada), chama-se mais-
valia relativa. (LIMA JÚNIOR et. al, 2014, p. 181).

No que se refere à produção de mais-valor absolutamente, o mero prolongamento da jornada de trabalho significa aumento absoluto da duração, mas não corresponde ao aumento da intensidade da jornada de trabalho. Num espaço de tempo de trabalho maior, isto é, numa jornada de trabalho prolongada, produz-se uma quantidade maior de valores-de-uso. No entanto, isto não é o mesmo que uma produção maior de valores-de-uso num dado espaço de tempo por exemplo, em $1 \mathrm{~h}$ de trabalho -, como ocorre no aumento da intensidade.

Já no que se refere à produção de mais-valor relativamente, essa se dá tanto pela redução do valor da força de trabalho, como enfatizam Lima Júnior et al. (2014), quanto em decorrência do aumento da intensidade e do aumento da produtividade do trabalho. Nas três situações, na verdade, a produção relativamente ampliada de mais-valor decorre da redução do trabalho necessário para aumentar o trabalho excedente sob uma mesma jornada de trabalho, como consequência da aplicação produtiva da ciência e da técnica revolucionando o modo de produção: a tal alteração na relação quantitativa entre trabalho excedente e trabalho necessário.

Especificamente, dado apenas o aumento relativo do mais-valor pelo aumento da intensidade do trabalho, apesar do valor incorporado a cada mercadoria não ser reduzido, mantendo então o seu preço, dá-se um aumento da quantidade de valores-de-uso produzidos, fazendo com que a quantidade de valor total produzido pela força de trabalho seja aumentada e o trabalho necessário de cada trabalhador seja reduzido, se fixado o valor pago à força de trabalho. Diferentemente, conforme Marx (2012a, p. 367-369), dado apenas o aumento relativo do mais-valor pelo aumento da produtividade do trabalho, tem-se a aceleração dos processos de produção de valores-de-uso, fazendo com que a quantidade de trabalho incorporado em cada unidade de mercadoria produzida seja menor, ou seja, o valor individual da mercadoria fica abaixo do seu valor social, sendo esse determinado pelo tempo de trabalho socialmente necessário. Isso decorre do fato de que "[...] a mesma variação da produtividade do trabalho que acresce o resultado do trabalho e, em consequência, a massa dos valores-de-uso que ele fornece reduz a magnitude do valor dessa massa global aumentada quando diminui o total do tempo 
do trabalho necessário para a sua produção" (MARX, 2012a, p. 68). Com mais valores-de-uso produzidos num dado espaço de tempo, a quantidade de valor total produzido pela força de trabalho pode ser aumentada e o trabalho necessário de cada trabalhador reduzido, se fixado o valor pago à força de trabalho. Como "[...] o verdadeiro valor de uma mercadoria não é, porém, o valor individual, e sim o valor social" (MARX, 2012a, p. 368), o capitalista individual cria as condições para se apropriar de um mais-valor extra em decorrência de uma maior exploração do trabalho produtivo vivo.

Com o tempo, para subsistirem no mercado e visando apropriar-se desse mais-valor excepcional, a própria competição impele outros capitalistas individuais a fazerem modificações científicas e tecnológicas no seu modo de produção, o que faz com que o mais-valor extra desapareça. Logo, não apenas os valores individuais, mas o próprio valor social da mercadoria é reduzido, por conta da diminuição do tempo de trabalho socialmente necessário para a sua obtenção, implicando na redução do seu preço.

Ademais, Lima Júnior et al. (2014) observam que a real motivação para a pesquisa científica e tecnológica e a inovação na contemporaneidade deve-se à produção de mais-valor relativo, o que é verdade, face à subsunção real do trabalho ao capital - incluindo o trabalho científico e técnico, tornando mesmo a ciência e a tecnologia como forças produtivas indispensáveis, no que se costuma denominar contemporaneamente de capitalismo cognitivo (GORZ, 2005; LAZZARATO; NEGRI, 2013) - e à necessidade daquele de ampliar incessantemente seus processos de valorização. No entanto, Lima Júnior et al. (2014) acreditam que só há aumento do mais-valor relativamente como consequência da redução do valor da força de trabalho, como se pode constatar nas passagens seguintes:

Qual é a relação entre a produção da mais-valia relativa e a incorporação de novas técnicas e novas tecnologias aos processos de produção de mercadoria? De que maneira inovações em C\&T contribuem para a redução do valor da força de trabalho? (LIMA JÚNIOR et. al, 2014, p. 182).

Marx (2010) destaca que algumas inovações tecnológicas e científicas contribuem para a redução do valor da força de trabalho (e, em consequência disso, para a produção de mais-valia relativa) na medida em que implicam a redução do trabalho médio necessário para produzir as mercadorias consumidas pela classe trabalhadora. (LIMA JÚNIOR et. al, 2014, p. 182).

[...] a redução do valor dos alimentos consumidos pelos trabalhadores implica a redução do valor da sua força de trabalho, e a redução do valor da força de trabalho, por sua vez, contribui para a produção da mais-valia relativa. (LIMA JÚNIOR et. al, 2014, p. 184).

Provavelmente, Lima Júnior et al. (2014) se assentam na seguinte afirmativa de Marx de que "[...] a taxa geral de mais-valia experimenta alteração relacionada com o processo por inteiro quando a elevação da produtividade do trabalho atinge ramos de produção, baixando preços das mercadorias que fazem parte do conjunto dos meios de subsistência que consti- 
tuem elementos do valor da força de trabalho" (MARX, 2012a, p. 370). No entanto, tal como discutido anteriormente, o desenvolvimento científico-tecnológico sob a forma capitalista de produção, que leva a mudanças no seu modo de produção, é motivado tanto pelo aumento da produtividade do trabalho, de sorte que a própria redução do valor da força de trabalho é uma consequência desse, quando atinge " $[. .$.$] os ramos industriais cujos produtos determinam o valor$ da força de trabalho" (MARX, 2012a, p. 366), quanto pelo aumento da intensidade do trabalho.

Em suma, no contexto da luta capitalista pela maximização da apropriação do maisvalor socialmente produzido, é justamente a possibilidade de se apropriar, mesmo que apenas momentânea e parcialmente, de um mais-valor relativo excepcional que impulsiona a inovação científica e tecnológica como "destruição criativa" - "destruindo" modos de produção antiquados e obsoletos para substituí-los por outros, mais novos, mais avançados, mais eficientes e mais produtivos - tal como definida por Schumpeter (1975, p. 81-86), e não a mera busca pela redução do valor da força de trabalho, tal como limitam Lima Júnior et al. (2014).

\section{Conclusão}

Ao se intentar compreender as várias nuanças das relações entre ciência, tecnologia e sociedade na contemporaneidade, uma perspectiva de análise crítica faz-se imprescindível. Uma vez que tem como elemento central o trabalho, o pensamento de Marx, especialmente, a sua teoria do mais-valor, incorpora a ciência e a técnica produtivamente aplicadas como eixos analíticos. A dialética do trabalho necessário e trabalho excedente e os conceitos de intensidade e aumento da produtividade do trabalho seriam inócuos sem levar em consideração as transformações nas relações sociais de produção decorrentes do desenvolvimento científico-tecnológico. Dada a subsunção real do trabalho ao capital, em que o mais-valor relativo assume um papel preponderante, as modificações nas forças produtivas face aos melhoramentos propiciados pela aplicação da ciência e da técnica são motivadas pelo aumento da intensidade e da produtividade do trabalho, reduzindo o trabalho necessário e convertendo-o em trabalho excedente.

Justamente por não se atentar devidamente às definições e às implicações da duração, intensidade e produtividade do trabalho em Marx, levando-os a identificar a redução do valor da força de trabalho como motivação fundamental do desenvolvimento capitalista das forças produtivas, Lima Júnior et al. (2014) fazem uso equivocado do conceito marxiano de mais-valor, pois o aumento da produtividade e da intensidade do trabalho estão associados ao aumento da produção de mais-valor relativamente, enquanto o prolongamento (ou aumento da duração) da jornada de trabalho à produção de mais-valor absolutamente.

Diversamente, esse trabalho procurou apontar, à luz da teoria do mais-valor de Marx e no contexto das relações CTS contemporâneas, que o que motiva o desenvolvimento tecnológico e científico sob a forma capitalista de produção é justamente a luta incessante entre os capitalistas de se apropriar de um mais-valor extra, ou seja, de maximizar o mais-valor relativamente extraído.

Espera-se que este trabalho contribua para o entendimento mais preciso da teoria do mais-valor de Marx e para o debate sobre a sua aplicação nas pesquisas em CTS, bem como na formação de pesquisadores no pensamento social crítico. 
Carvalho, H. J. R.; Zanin, M.; Shimbo, I.

\section{Referências}

COTRIM, V. Trabalho produtivo em Marx: novas e velhas questões. São Paulo: Record, 2013.

GORZ, A. O imaterial: conhecimento, valor e capital. Rio de Janeiro: Annablume, 2005.

FEENBERG, A. Ciencia, tecnología y democracia: distinciones y conexiones. Scientiae Studia, São Paulo, v. 7, n. 1, p. 63-81, 2009. Disponível em: < https://doi.org/10.1590/ S1678-31662009000100004 >. Acesso em: 19 out. 20

LAZZARATO, M.; NEGRI, A. Trabalho imaterial: formas de vida e produção da subjetividade. 2. ed. Rio de Janeiro: Lamparina, 2013.

LIMA JÚNIOR, P. et al. Marx como referencial para análise de relações entre ciência, tecnologia e sociedade. Ciência \& Educação, Bauru, v. 20, n. 1, p. 175-194, 2014. Disponível em: <https://doi.org/10.1590/1516-731320140010011>. Acesso em: 19 out. 2017.

LINHART, D. A desmedida do capital. São Paulo: Boitempo, 2007.

MARX, K. Grundrisse. São Paulo: Boitempo, 2011.

O capital: livro 1, volume 1. São Paulo: Civilização Brasileira, 2012a.

O capital: livro 1, volume 2. São Paulo: Civilização Brasileira, 2012b.

MORAES NETO, B. R. Marx, Taylor e Ford: as forças produtivas em discussão. São Paulo: Brasiliense, 1989.

NOVAES, H.; DAGNINO, R. Fetiche da tecnologia. Org \& Demo, Marília, v. 5, n. 2, p. 189-2010, 2004.

POSTONE, M. Tempo, trabalho e dominação social. São Paulo: Boitempo, 2014.

REICHELT, H. Sobre a estrutura lógica do conceito de capital em Karl Marx.

Campinas: Editora Unicamp, 2013.

ROMERO, D. Marx e a técnica, um estudo dos manuscritos de 1861-1862. São Paulo: Expressão Popular, 2007.

RUBIN, I. I. A teoria marxista do valor. São Paulo: Brasiliense, 1980.

SCHUMPETER, J. Capitalism, socialism and democracy. New York: Harper Colophon Books, 1975.

WINNER, L. Upon opening the black box and fiding it empty: social construtivism and philosophy of technology. Science, Technology \& Human Values, Thousand Oaks, v. 18, n. 3, p. 362-378, 1993.

Artigo recebido em 25/05/2016. Aceito em 25/05/2017.

Endereço para contato: Universidade Federal de São Carlos,

Programa de Pós-graduação em Ciência Tecnologia e Sociedade, São

Carlos-SP, CEP 13565-905, Brasil. 